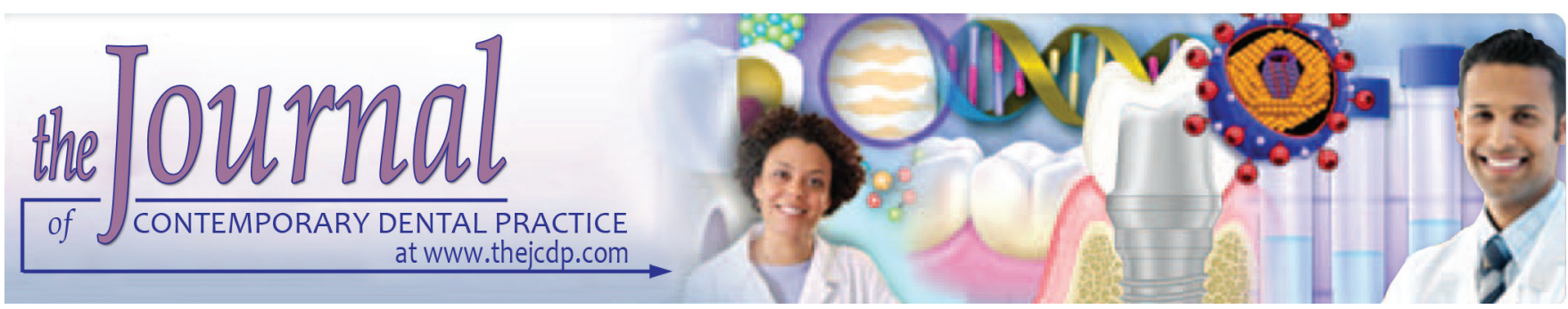

\title{
Radiopacity of 28 Composite Resins for Teeth Restorations
}

\author{
${ }^{1}$ Ricardo Raitz, ${ }^{2}$ Patrizia Dubinskas Moruzzi, ${ }^{3}$ Glauco Vieira, ${ }^{4}$ Marlene Fenyo-Pereira
}

\begin{abstract}
Aim: Radiopacity is a fundamental requisite to check marginal adaptation of restorations. Our objective was to assess the radiopacity of 28 brands of light-cured composite resins and compare their radiopacity with that of enamel, dentin, and aluminum of equivalent thickness
\end{abstract}

Materials and methods: Composite resin disks $(0.2,0.5$, and $1 \mathrm{~mm}$ ) were radiographed by the digital method, together with an aluminum penetrometer and a human tooth equivalent tooth section. The degree of radiopacity of each image was quantified using digital image processing. Wilcoxon nonparametric test was used for comparison of the mean thickness of each material.

Results: All of the materials tested had an equal or greater radiopacity than that of aluminum of equivalent thickness. Similar results for enamel were found with the exception of Durafill, which was less radiopaque than enamel $(p<0.05)$. All the specimens were more radiopaque than dentin, except for P90 (which was equally radiopaque) and Durafill (which was less radiopaque). The thickness of the specimens may influence the similarity to the enamel's radiopacity. All of the composite resins comply with specification \#27 of the American Dental Association. The radiopacity of Amelogen Plus, Aph, Brilhiante, Charisma, Concept Advanced, Evolux X, Exthet X, Inten S, Llis, Master Fill, Natural Look, Opallis, P60, Tetric, Tph, Z100, and Z250 was significantly higher than that of enamel $(p<0.05)$.

Conclusion: With these composites, it is possible to observe the boundaries between restoration and tooth structure, thus allowing clinicians to establish the presence of microleakage or restoration gap.

\footnotetext{
${ }^{1}$ Department of Oral Pathology, Oral Diagnosis and Oral Radiology, São Leopoldo Mandic Research Center, São Paulo, Brazil

${ }^{2}$ Department of Radiology, School of Dentistry, Braz Cubas University, Mogi das Cruzes, São Paulo, Brazil

${ }^{3}$ Department of Restorative Dentistry, School of Dentistry University of São Paulo (FOUSP), São Paulo, Brazil

${ }^{4}$ Department of Stomatology, School of Dentistry, University of São Paulo (FOUSP), São Paulo, Brazil

Corresponding Author: Ricardo Raitz, Professor, Department of Oral Pathology, Oral Diagnosis and Oral Radiology, São Leopoldo Mandic Research Center, São Paulo, Brazil, Phone: +551136735270, e-mail: ricardoraitz@ig.com.br
}

Clinical significance: Suitable radiopacity is an essential requisite for good-quality esthetic restorative materials. We demonstrate that only some composites have the sufficient radiopacity to observe the boundaries between restoration and tooth structure, which is the main cause of restoration failure.

Keywords: Composite resins, Digital radiography, Image processing.

How to cite this article: Raitz R, Moruzzi PD, Vieira G, FenyoPereira M. Radiopacity of 28 Composite Resins for Teeth Restorations. J Contemp Dent Pract 2016;17(2):136-142.

\section{Source of support: Nil}

Conflict of interest: None

\section{INTRODUCTION}

The development of dentinal adhesive systems has made the use of composite resins in both anterior and posterior teeth routine in clinical practice. The radiopacity of restorative materials is an essential requisite for assessing restoration overcontouring, marginal adaptation defects, such as overhangs and gaps, caries relapse, excessive proximity to the pulp, and the lack of a contact point, among other unfavorable conditions, thus contributing to radiographic diagnosis. ${ }^{1,2}$

To date, no consensus has been reached on the ideal degree of radiopacity of esthetic restorative materials. However, measurement of radiopacity has been standardized by two sets of guidelines. Specification \#27 of the American Dental Association (ADA) ${ }^{3}$ states that a composite resin should have the radiopacity equivalent to 1-mm-thick sample of aluminum, which is approximately equal to natural tooth dentin. Requirements established by the Organization for Standards (ISO/DP 4049) ${ }^{4}$ specify that the radiopacity of a $2-\mathrm{mm}$-thick specimen of the material should be equal to that of a $2 \mathrm{~mm}$ or larger thickness of aluminum.

One of the techniques used to evaluate the radiopacity of dental materials is to compare a specific thickness of a composite with an aluminum step wedge of known thickness under controlled radiographic conditions. The radiopacity of a dental material specimen is usually expressed 
in terms of equivalent aluminum thickness (millimeters) using a reference calibration curve. The radiopacity of composite resins has been studied extensively, but most research has used test specimens of 1,2 mm or even greater thickness, ${ }^{2,5-8}$ which are potentially too thick to indicate the radiopacity of less thick restoration areas that are often observed in clinical practice.

There are several types and brands of composite resins on the market with various degrees of radiopacity. This variation has been a major complaint among dentists because it may lead them to mistake presumed microleakages for the restorative material itself.

The aim of the present study is to assess the radiopacity of 28 brands of light-cured composite resins for direct use, available on the market, using a digital imaging method and to compare their radiopacity with that of enamel, dentin, and aluminum of equivalent thickness.

\section{MATERIALS AND METHODS}

\section{Composite Resin Specimens}

A set of 28 brands of light-cured composite resins was studied (Table 1). Three disks of each of three different thicknesses $(0.2,0.5$, and $1 \mathrm{~mm})$ were manufactured,

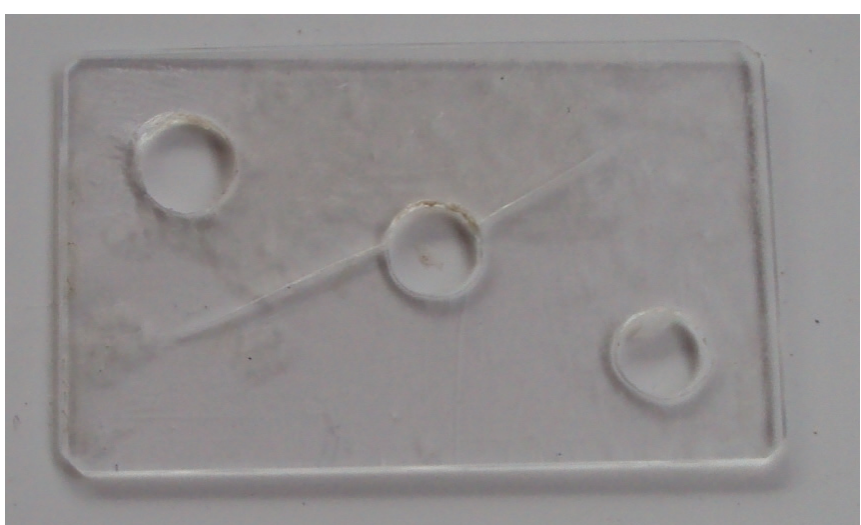

Fig. 1: Acetate matrix with perforations for inserting the material

totaling nine disks of each material. These different thicknesses were used to simulate the various clinical possibilities encountered by dentists. The composite resin disks were made using three different thickness acetate matrices, which were perforated by a wheel-mounted diamond bur, through which the resin was inserted (Fig. 1). The resin was then pressed using a polyester strip.

The disks were light-cured according to the manufacturers' recommendations using an Ultra light-emitting diode light-curing unit and finished with medium-, fine-, and extra-fine-grit Sof Lex disks (3M ESPE, St Paul,

Table 1: Composite resins analyzed in the study

\begin{tabular}{|c|c|c|c|c|}
\hline Brand & Manufacturer & Country of origin & Indication & Shade \\
\hline Amaris & Voco & Germany & Anterior/posterior & A2 \\
\hline Amelogen Plus & Ultradent & USA & Anterior/posterior & $\mathrm{A} 2$ \\
\hline Aph & Dentsply & USA & Posterior & $\mathrm{A} 2$ \\
\hline Brilhiante & Vigodent & Brazil & Anterior/posterior & $\mathrm{A} 2$ \\
\hline Charisma & Heraeus-Kulzer & Germany & Anterior/posterior & $\mathrm{A} 2$ \\
\hline Concept Advanced & Vigodent & Brazil & Anterior/posterior & $\mathrm{A} 2$ \\
\hline Evolux $X$ & Dentsply & USA & Anterior/posterior & $\mathrm{A} 2$ \\
\hline Exthet X & Dentsply & USA & Anterior/posterior & $\mathrm{A} 2$ \\
\hline Glacier & SDI & Australia & Anterior/posterior & $\mathrm{A} 2$ \\
\hline Grandio & Voco & Germany & Anterior/posterior & $\mathrm{A} 2$ \\
\hline Ice & SDI & Australia & Anterior/posterior & $\mathrm{A} 2$ \\
\hline Inten S & Ivoclair-Vivadent & Germany & Anterior/posterior & $\mathrm{A} 2$ \\
\hline Master Fill & Biodinâmica & Brazil & Anterior/posterior & $\mathrm{A} 2$ \\
\hline Natural Look & DFL & Brazil & Anterior/posterior & $\mathrm{A} 2$ \\
\hline Opallis & FGM & Brazil & Anterior/posterior & $\mathrm{A} 2$ \\
\hline P60 & 3M ESPE & USA & Posterior & $\mathrm{A} 2$ \\
\hline P90 & 3M ESPE & USA & Posterior & $\mathrm{A} 2$ \\
\hline Rock & SDI & Australia & Posterior & $\mathrm{A} 2$ \\
\hline Supreme & 3M ESPE & USA & Anterior/posterior & $\mathrm{A} 2$ \\
\hline Tetric & Ivoclair-Vivadent & Germany & Anterior/posterior & $\mathrm{A} 2$ \\
\hline Tph & Dentsply & USA & Anterior/posterior & $\mathrm{A} 2$ \\
\hline Venus & Heraeus-Kulzer & Germany & Anterior/posterior & A2 \\
\hline Vit L Escence & Ultradent & USA & Anterior/posterior & $\mathrm{A} 2$ \\
\hline Z100 & 3M ESPE & USA & Anterior/posterior & $\mathrm{A} 2$ \\
\hline
\end{tabular}


Minnesota, USA). Thickness was verified with a digital pachymeter.

\section{Teeth Specimens}

The three different thicknesses were also simulated on two teeth specimens, which were donated by the University Tooth Bank. These teeth were used as a radiopacity reference for enamel and dentin for comparison with the composite resin specimens. They were first stored in water and then embedded in acrylic resin, positioned and cut into 0.5 and 1-mm-thick pieces (premolar and canine) using a precision cutting machine (IsoMet 1000; Buehler, Lake Bluff, IL, USA). Finishing was done with an automatic grinding and polishing machine (Ecomet-3; Buehler, IL, USA). A 0.2-mm-thick tooth section was obtained by grinding one of the $0.5 \mathrm{~mm}$ sections with a micromotor and sandpaper disk. After grinding, the size was verified with a digital pachymeter (Fig. 2).

\section{Digital Analysis of Radiopacity}

The resin disks were placed on a horizontal table over a size-2 phosphor plate sensor (New Digora Optime Soredex 2009, Tuusula, Finland), in groups of 3 by 3 and side by side (grouped by the same brand and same thickness). Each group was imaged together with a tooth section prepared at the same thickness for radiopacity assessment. An aluminum penetrometer containing six steps, the first measuring $0.2 \mathrm{~mm}$, the second $0.5 \mathrm{~mm}$, and

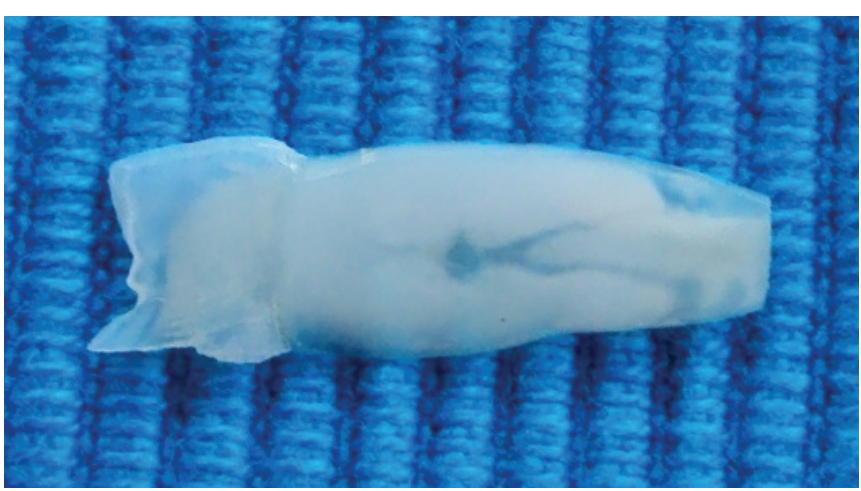

Fig. 2: Finished tooth section used in the study

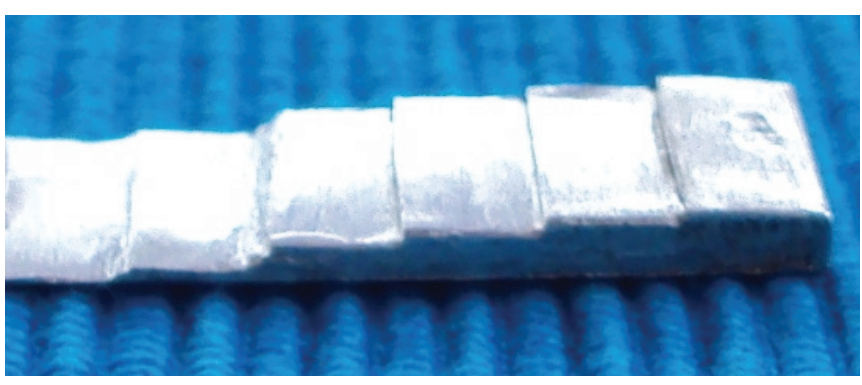

Fig. 3: Profile view of the aluminum penetrometer the others increasing $0.5 \mathrm{~mm}$ at each step, was also used in all the assessments (Fig. 3). All steps were also verified with a digital pachymeter.

The X-ray apparatus (Intrex VSK; Keystone, Burlington, USA) was set to operate at $70 \mathrm{kVp}, 10 \mathrm{~mA}$, and an exposure time of 0.2 seconds. A focal distance of $30 \mathrm{~cm}$ was standardized using a film holder. This film holder was only used to standardize the correct distance of the X-ray cone, as is commonly used for obtaining periapical radiographs using the paralleling technique.

Processing was performed with a scanner (New Digora Optime; Soredex 2009, Tuusula, Finland) coupled to a personal computer (Hewlett-Packard, Palo Alto, USA). The images were saved in DICOM format and then imported into a dental imaging program (Kodak, Atlanta, USA) to perform the radiopacity readings. The readings were made based on pixel intensity, with values ranging from 0 to 255, where 0 represented black (completely radiolucent) and 255 represented white (completely radiopaque).

A dental imaging program (Kodak, Atlanta, USA) was used to draw 8-mm lines through the central regions on the enamel and dentin layers, the central portion of the step corresponding to the aluminum scale, and the central portion of each composite resin disk. Radiopacity readings were made on three equidistant points along a line (Fig. 4). The arithmetic mean of the three readings obtained for each material was considered its final radiopacity value.

Data were tabulated using Microsoft Excel, Wilcoxon nonparametric test was used for the comparisons, and a $5 \%$ significance level was used. A statistically significant radiopacity difference between the materials tested and also between the comparisons performed with the different reference materials was recorded when the $\mathrm{p}$ value was smaller than $0.05(\mathrm{p}<0.05)$.

This study was submitted to and approved by the research ethics committee of the institution where the research was conducted.

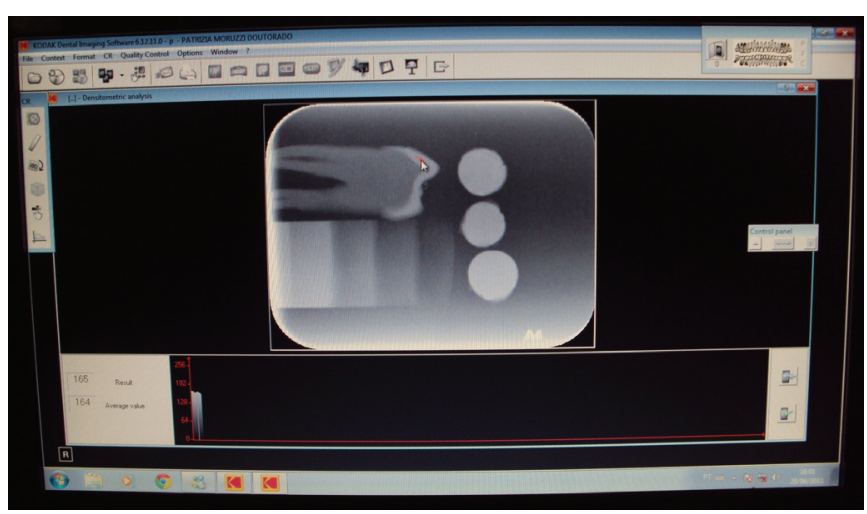

Fig. 4: Kodak dental imaging software used for the radiopacity readings 


\section{RESULTS}

The mean results obtained for the test specimens were compared with those of each of the reference materials: enamel, dentin, and aluminum. Three thicknesses were considered for comparison. Therefore, each composite resin brand had a sample size of nine measurements (three repetitions in three thicknesses, 0.2, 0.5, and $1 \mathrm{~mm}$ ). For statistical analysis, the mean of these three thicknesses for each material was considered (Table 2).

\section{Comparing the Test Specimen Results to Those of the Three Reference Materials: Enamel, Dentin, and Aluminum}

\section{Test Specimen vs Enamel}

There was no difference between the results obtained for enamel and those obtained for the test specimens for the following composite resins: Amaris, Glacier, Grandio, Ice, P90, Rock, Supreme, Venus, Vit Escence, and Z350 $(\mathrm{p}>0.05)$.

The radiopacity of Amelogen Plus, Aph, Brilhiante, Charisma, Concept Advanced, Evolux X, Exthet X, Inten S, Llis, Master Fill, Natural Look, Opallis, P60, Tetric,
Tph, Z100, and Z250 was higher than that of enamel $(\mathrm{p}<0.05)$.

The radiopacity of Durafill was lower than that of enamel $(p<0.05)$ (Table 2$)$.

\section{Test Specimens vs Dentin}

There was no difference between dentin and P90 $(\mathrm{p}>0.05)$.

The radiopacity of Amaris, Amelogen Plus, Aph, Brilhiante, Charisma, Concept Advanced, Evolux $X$, Exthet X, Glacier, Grandio, Ice, Inten S, Llis, Master Fill, Natural Look, Opallis, P60, Rock, Supreme, Tetric, Tph, Venus, Vit Escence, Z100, Z250, and Z350 was higher than that of dentin $(\mathrm{p}<0.05)$.

The radiopacity of Durafill was lower than that of dentin $(\mathrm{p}<0.05)$ (Table 2).

\section{Test Specimen vs Aluminum}

The only composite resin that did not present a statistically significant difference ( $p>0.05$ ) was Durafill, which proved to have a radiopacity similar to aluminum. The radiopacity of all other brands was higher than that of aluminum $(\mathrm{p}<0.05)$ (Table 2$)$.

Table 2: Mean radiopacity value of the composite resin test specimens compared with those of enamel, dentin, and aluminum

\begin{tabular}{|c|c|c|c|c|c|c|c|c|}
\hline \multirow[b]{2}{*}{ Composite resin } & \multicolumn{2}{|c|}{ Test specimen } & \multicolumn{2}{|c|}{ Enamel } & \multicolumn{2}{|c|}{ Dentin } & \multicolumn{2}{|c|}{ Aluminum } \\
\hline & Mean & Standard deviation & Mean & $p$-value & Mean & $p$-value & Mean & $p$-value \\
\hline Amaris & 137.3 & 29.1 & 138.7 & 0.813 & 111.7 & 0.001 & 102.1 & 0.008 \\
\hline Amelogen Plus & 170.3 & 38.8 & 141.8 & 0.028 & 107.6 & 0.008 & 104.6 & 0.008 \\
\hline Aph & 168.7 & 44.4 & 132.9 & 0.008 & 112.7 & 0.008 & 106.0 & 0.008 \\
\hline Brilhiante & 162.6 & 40.8 & 128.6 & 0.008 & 106.2 & 0.008 & 105.0 & 0.008 \\
\hline Charisma & 155.4 & 34.5 & 130.1 & 0.008 & 111.8 & 0.008 & 98.4 & 0.008 \\
\hline Concept Advanced & 158.9 & 37.0 & 140.1 & 0.011 & 117.1 & 0.008 & 104.8 & 0.008 \\
\hline Durafill & 95.6 & 11.1 & 144.3 & 0.008 & 121.4 & 0.008 & 105.3 & 0.066 \\
\hline Evolux X & 174.9 & 42.8 & 131.4 & 0.008 & 111.4 & 0.008 & 105.7 & 0.008 \\
\hline Exthet $X$ & 168.1 & 41.1 & 138.0 & 0.008 & 113.4 & 0.008 & 108.3 & 0.008 \\
\hline Glacier & 137.0 & 21.2 & 129.0 & 0.110 & 109.1 & 0.008 & 106.6 & 0.008 \\
\hline Grandio & 140.6 & 24.4 & 141.0 & 0.953 & 115.7 & 0.008 & 105.9 & 0.008 \\
\hline Ice & 125.7 & 19.9 & 129.8 & 0.515 & 109.3 & 0.008 & 104.2 & 0.008 \\
\hline Inten S & 172.9 & 40.7 & 135.9 & 0.008 & 112.2 & 0.008 & 97.8 & 0.008 \\
\hline Llis & 160.2 & 41.9 & 128.4 & 0.011 & 109.2 & 0.008 & 109.0 & 0.008 \\
\hline Master Fill & 150.1 & 33.3 & 140.3 & 0.036 & 115.3 & 0.008 & 101.7 & 0.008 \\
\hline Natural Look & 169.2 & 43.3 & 121.9 & 0.008 & 104.6 & 0.008 & 102.7 & 0.008 \\
\hline Opallis & 150.3 & 29.6 & 135.4 & 0.028 & 114.6 & 0.008 & 112.6 & 0.011 \\
\hline P60 & 145.9 & 33.7 & 131.9 & 0.021 & 112.3 & 0.008 & 102.3 & 0.011 \\
\hline P90 & 119.3 & 14.4 & 137.4 & 0.139 & 117.8 & 0.594 & 106.8 & 0.021 \\
\hline Rock & 125.3 & 19.2 & 126.3 & 0.953 & 107.4 & 0.011 & 106.4 & 0.011 \\
\hline Supreme & 135.6 & 30.8 & 136.4 & $>0.999$ & 115.0 & 0.008 & 104.0 & 0.012 \\
\hline Tetric & 175.7 & 44.4 & 130.0 & 0.008 & 110.2 & 0.008 & 99.4 & 0.008 \\
\hline Tph & 172.5 & 44.2 & 133.7 & 0.008 & 112.8 & 0.008 & 104.2 & 0.008 \\
\hline Venus & 150.9 & 32.6 & 142.6 & 0.401 & 118.8 & 0.015 & 101.3 & 0.008 \\
\hline Vit L Escence & 128.3 & 22.5 & 121.8 & 0.400 & 105.6 & 0.011 & 107.9 & 0.011 \\
\hline Z100 & 156.4 & 32.1 & 135.6 & 0.011 & 115.0 & 0.008 & 108.0 & 0.011 \\
\hline Z250 & 149.3 & 28.1 & 135.1 & 0.015 & 111.7 & 0.008 & 107.1 & 0.008 \\
\hline $\mathrm{Z350}$ & 141.1 & 26.8 & 136.2 & 0.514 & 112.9 & 0.011 & 107.7 & 0.011 \\
\hline
\end{tabular}


Table 3: Comparison between the radiopacity levels of the studied composite resins and those of the reference materials, according to the thicknesses of $0.2,0.5$, and $1 \mathrm{~mm}$

\begin{tabular}{|c|c|c|c|c|c|c|c|c|c|c|c|c|}
\hline \multirow[b]{2}{*}{ Composite resin } & \multicolumn{12}{|c|}{ Material/thickness $(\mathrm{mm})$} \\
\hline & $E$ & $D$ & $A$ & $T$ & $E$ & $D$ & $A$ & $T$ & $E$ & $D$ & $A$ & $T$ \\
\hline & 0.2 & 0.2 & 0.2 & 0.2 & 0.5 & 0.5 & 0.5 & 0.5 & 1 & 1 & 1 & 1 \\
\hline Amaris & 103 & 98 & 85 & 109 & 144 & 118 & 97 & 132 & 169 & 119 & 124 & 172 \\
\hline Amelogen Plus & 130 & 92 & 96 & 127 & 119 & 107 & 103 & 172 & 176 & 123 & 115 & 212 \\
\hline Aph & 102 & 97 & 99 & 121 & 123 & 107 & 105 & 165 & 174 & 134 & 114 & 220 \\
\hline Brilhiante & 99 & 95 & 87 & 118 & 140 & 109 & 108 & 160 & 146 & 114 & 120 & 210 \\
\hline Charisma & 97 & 94 & 90 & 119 & 120 & 107 & 97 & 154 & 173 & 135 & 108 & 193 \\
\hline Concept Advanced & 100 & 95 & 94 & 118 & 144 & 118 & 109 & 158 & 176 & 138 & 112 & 200 \\
\hline Durafill & 132 & 116 & 92 & 96 & 123 & 109 & 105 & 94 & 178 & 139 & 118 & 97 \\
\hline Evolux X & 102 & 94 & 95 & 128 & 122 & 106 & 108 & 175 & 170 & 135 & 114 & 222 \\
\hline Exthet $X$ & 101 & 93 & 104 & 123 & 147 & 115 & 102 & 167 & 166 & 132 & 119 & 214 \\
\hline Glacier & 105 & 96 & 95 & 121 & 118 & 108 & 105 & 128 & 164 & 123 & 119 & 162 \\
\hline Grandio & 109 & 102 & 100 & 116 & 142 & 110 & 108 & 139 & 172 & 135 & 110 & 167 \\
\hline Ice & 103 & 98 & 95 & 111 & 121 & 105 & 100 & 118 & 166 & 126 & 118 & 148 \\
\hline Inten S & 101 & 96 & 97 & 130 & 139 & 108 & 84 & 170 & 168 & 132 & 112 & 219 \\
\hline Llis & 99 & 92 & 93 & 114 & 120 & 104 & 107 & 159 & 166 & 131 & 127 & 208 \\
\hline Master Fill & 105 & 100 & 86 & 115 & 144 & 113 & 106 & 149 & 172 & 133 & 113 & 186 \\
\hline Natural Look & 100 & 90 & 91 & 120 & 124 & 111 & 101 & 172 & 142 & 112 & 116 & 216 \\
\hline Opallis & 105 & 94 & 104 & 118 & 124 & 114 & 108 & 149 & 178 & 136 & 125 & 183 \\
\hline P60 & 99 & 91 & 93 & 108 & 123 & 109 & 100 & 147 & 174 & 137 & 114 & 182 \\
\hline P90 & 103 & 96 & 100 & 106 & 128 & 116 & 105 & 120 & 181 & 141 & 116 & 132 \\
\hline Rock & 99 & 93 & 99 & 108 & 115 & 101 & 106 & 121 & 165 & 129 & 115 & 147 \\
\hline Supreme & 103 & 94 & 95 & 104 & 125 & 107 & 105 & 130 & 181 & 143 & 112 & 172 \\
\hline Tetric & 98 & 89 & 89 & 128 & 122 & 108 & 99 & 174 & 170 & 133 & 110 & 226 \\
\hline Tph & 107 & 95 & 97 & 125 & 124 & 108 & 103 & 169 & 171 & 135 & 113 & 223 \\
\hline Venus & 132 & 116 & 87 & 119 & 127 & 112 & 98 & 147 & 168 & 129 & 119 & 187 \\
\hline Vit L Escence & 102 & 97 & 97 & 111 & 125 & 111 & 108 & 124 & 138 & 109 & 118 & 150 \\
\hline Z100 & 101 & 92 & 105 & 126 & 124 & 108 & 106 & 150 & 181 & 144 & 113 & 193 \\
\hline Z250 & 102 & 91 & 95 & 123 & 129 & 111 & 105 & 145 & 175 & 133 & 121 & 180 \\
\hline Z350 & 103 & 96 & 98 & 113 & 122 & 104 & 109 & 145 & 183 & 139 & 115 & 165 \\
\hline
\end{tabular}

E: Enamel; D: Dentin; A: Aluminum; T: Test specimen; Values in pixels

\section{Comparing All Brands to the Reference Materials, Considering All Thicknesses}

We quantitatively compared the results obtained for each material (enamel, dentin, and aluminum) with those obtained for the test specimens of different thicknesses (Table 3).

The 0.2-mm test specimen results closest to those of enamel were those obtained for Amaris, Amelogen Plus, and Supreme. The radiopacity of Durafill and Venus was lower than that of enamel and that of dentin. All resins had a radiopacity similar to or higher than that of aluminum.

The $0.5-\mathrm{mm}$ test specimen results closest to those of enamel were those obtained for Amaris, Ice, Rock Supreme, and VIT Escence. Durafill was the only composite resin that showed a radiopacity level lower than that of enamel, lower than that of dentin, and lower than that of aluminum.

The 1-mm test specimen results closest to those of enamel were those obtained for Amaris, Glacier, Grandio,
Opalis, P60, and Z250. The radiopacity of Durafill was lower than that of enamel, lower than that of dentin, and lower than that of aluminum.

\section{DISCUSSION}

Light-cured composite resins were introduced to replace amalgam for restoring posterior teeth. They present different levels of radiopacity, as demonstrated in our study. When placing a restoration, it is essential to be able to distinguish the tooth, the restoration, and the carious lesion to avoid false diagnoses. . $^{1,2,9,10}$

Opinions vary greatly in the related literature as to the level of radiopacity that composite resins should have. Some authors only stress that the material must be radiopaque ${ }^{11}$ whereas others state that the material radiopacity level should be equal to or greater than that of dentin, which is the acceptable inferior limit of radiopacity. ${ }^{1,2}$ Most authors, however, agree that the radiopacity level of the material should be equal to or greater than that of enamel. ${ }^{7,9,10,12-15}$ We agree with 
this last definition because it is difficult to detect secondary caries, to check the contour, and to check for complete filling of the cavity accurately when the radiopacity of the restorative material is similar to, or lower than, that of dentin. This difficulty still exists when the radiopacity level of the material is lower than, or equal to, that of enamel, but is restricted to the areas where the restoration is in contact with the tooth structure. We may thus conclude that the clinically ideal radiopacity for a restorative material would be higher than that of enamel. ${ }^{16}$ Even though the superior limit has not been established, some authors argue that very radiopaque materials, such as amalgam, impair radiographic identification of marginal adaptation, recurrent caries, and other defects. ${ }^{17}$

The related literature presents many methods for investigating the degree of radiopacity of materials. The procedure of comparing the radiopacity level of one given material to that of another - that serves as a reference-is common to all methods. Aluminum is considered the choice reference material by some authors. ${ }^{11,12,18}$ Tooth sections with thicknesses equivalent to those of the material under investigation are used in other works. ${ }^{2,5,13,19}$ Still other investigators combined both types; they compared samples of the studied material with aluminum and with tooth sections, ${ }^{1,6,7,20-26}$ as in our experiment. Using this method, we observed that dentin does not always have the same radiopacity as its aluminum equivalent (Table 3). Therefore, in our opinion, the conversion of the optical density (or pixel values) of samples to equivalent millimeters of aluminum ( $\mathrm{mm} \mathrm{Al}$ ) should be used with caution as it may produce approximate but not exact values compared with that of dentin.

Another important detail that should be considered is the test specimen thickness. Different thicknesses are found in the related literature: $3 \mathrm{~mm},{ }^{2,6,23} 2.5 \mathrm{~mm},{ }^{9,13,15,21}$ $2 \mathrm{~mm},{ }^{5-7,20,23}$ and $1 \mathrm{~mm} \cdot{ }^{6,8,23}$ Our study used test specimen thicknesses lower than those found in the literature, namely $0.2,0.5$, and $1 \mathrm{~mm}$ to better approximate our study conditions to actual clinical situations where thinner layers are often used. Our results showed that the mean radiopacity degree (of the three thickness) of Amaris, Glacier, Grandio, Ice, P90, Rock, Supreme, Venus, Vit Escence, and Z350 was similar to that of enamel ( $p>0.05)$. It is thus clinically infeasible to distinguish enamel and restoration at the tooth/restorative material interface with these composites. Consequently, imperfections may go undetected, ultimately leading to false positives or false negatives while diagnosing caries in this region (Table 2).

The radiopacity of Amelogen Plus, Aph, Brilhiante, Charisma, Concept Advanced, Evolux X, Exthet X, Inten S, Llis, Master Fill, Natural Look, Opallis, P60, Tetric, Tph, Z100, and Z250 was significantly higher than that of enamel $(p<0.05)$. With these composites, it is possible to observe the boundaries between restoration and tooth structure, thus affording confidence to the clinician in establishing a diagnosis of microleakage or restoration gap. These results are consistent with those of Hara et $\mathrm{al}^{26}$ who have already demonstrated that the radiopacity of Z100 was higher than that of the tooth structure, and those of Salzedas et al, ${ }^{7}$ who demonstrated that the radiopacity of Charisma, Z100, and Tph was equal to or higher than that of enamel.

The radiopacity of $\mathrm{P} 90$ was considered to be statistically similar to that of dentin ( $p>0.05)$, which means it will not be possible to accurately distinguish dentin structures from restorative material at their interface when this material is used. The radiopacity of Amaris, Amelogen plus, Aph, Brilhiante, Charisma, Concept Advanced, Evolux X, Exthet X Glacier, Grandio, Ice, Inten S, Llis, Master Fill, Natural Look, Opallis, P60, Rock, Supreme, Tetric, Tph, Venus, Vit Escence, Z100, Z250, and Z350 was higher than that of dentin $(\mathrm{p}<0.05)$.

The radiopacity of Durafill, on the other hand, proved lower than that of enamel and dentin $(\mathrm{p}<0.05)$, rendering its clinical use difficult, insofar as it may be radiographically mistaken for a caries infiltration or for a restoration gap.

The only resin whose radiopacity was not significantly different from that of aluminum was Durafill ( $p>0.05$ ). These results show that, on average, this brand's radiopacity was statistically similar to that of aluminum, justifying its compliance with specification \#27 of the $\mathrm{ADA}^{27}$ and its place in the market. All other resins proved more radiopaque than aluminum $(\mathrm{p}>0.05)$.

However, conditions closer to the clinical reality may be depicted by using different thickness. Table 3 shows the quantitative analysis of the different thicknesses of the materials. The radiopacity of the $0.2 \mathrm{~mm}$ test specimens made with the Durafill and Venus composites was lower than that of enamel and represents the worst results. The radiopacity of the $0.2 \mathrm{~mm}$ test specimens made with the Durafill composite was lower than that of dentin, confirming the results obtained when Durafill was compared with aluminum. The radiopacity of the 0.5 and $1 \mathrm{~mm}$ test specimens made with Durafill was lower than that of enamel, dentin, and aluminum. The thickness of the specimens may influence the observed radiopacity and, therefore, the similarity to enamel. Based on this observation, we suggest that further investigations be conducted on the radiopacity of this brand using specimens with different thicknesses.

\section{CONCLUSION}

All of the composite resins tested comply with specification \#27 of the ADA. 
The radiopacity of Amelogen Plus, Aph, Brilhiante, Charisma, Concept Advanced, Evolux X, Exthet X, Inten S, Llis, Master Fill, Natural Look, Opallis, P60, Tetric, Tph, Z100, and Z250 was significantly higher than that of enamel $(p<0.05)$. With these composites, it is possible to observe the boundaries between restoration and tooth structure, thus enabling clinicians to accurately establish a diagnosis of microleakage or restoration gap.

\section{CLINICAL SIGNIFICANCE}

Suitable radiopacity is an essential requisite for goodquality esthetic restorative materials. We demonstrate that only some composites have the sufficient radiopacity to observe the boundaries between restoration and tooth structure, which is the main cause of restoration failure.

\section{REFERENCES}

1. Cook WD. An investigation of radiopacity of composite restorative materials. Aust Dent J 1981;26(2):105-112.

2. Prévost AP, Forest D, Tanguay R, DeGrandmont P. Radiopacity of glass ionomer dental materials. Oral Surg Oral Med Oral Pathol Oral Radiol Endod 1990 Aug;70(2):231-235.

3. American Dental Association-Division of Science on behalf of the ADA Council on Scientific Affairs. Resin-based composites. J Am Dent Assoc 2003 Apr;134(4):510-512.

4. ISO Standards. ISO 4049 dentistry-polymer-based filling, restorative and luting material. 3rd ed. Geneva: International Organization for Standardization; 2000. p. 3-5.

5. Stanford CM, Fan PL, Schoenfeld CM, Knoeppel R, Stanford JW. Radiopacity of light-cured posterior composite resins. J Am Dent Assoc 1987 Nov;115(5):722-724.

6. Curtis PMJr, Von Fraunhofer JA, Farman AG. The radiographic density of composite restorative resins. Oral Surg Oral Med Oral Pathol Oral Radiol Endod 1990 Aug;70(2):226-230.

7. Salzedas LM, Louzada MJ, Oliveira Filho AB. Radiopacity of restorative materials using digital images. J Appl Oral Sci 2006 Apr;14(2):147-152.

8. Ergücü Z, Türkün LS, Onem E, Güneri P. Comparative radiopacity of six flowable resin composites. Oper Dent 2010 Jul-Aug;35(4):436-440.

9. Omer OE, Wilson NHF, Watts DC. Radiopacity of posterior composites. J Dent 1986 Aug;14(4):178-179.

10. Goshima T, Goshima Y. The optimum level of radiopacity in posterior composite resins. Dentomaxillofac Radiol 1989 Feb;18(1):19-21.

11. Akerboom HBM, Kreulen CM, Van Amerongen WE, Mol A. Radiopacity of posterior composite resins, composite resin luting cements and glass ionomer lining cements. J Prosthet Dent 1993 Oct;70(4):351-355.
12. Goshima T, Goshima Y. Radiographic detection of recurrent carious lesion associated with composite restorations. Oral Surg Oral Med Oral Pathol Oral Radiol Endod 1990 Aug;70(2):236-239.

13. Abou-Tabl ZM, Tidy DC, Combe EC. Radiopacity of composite restorative materials. Br Dent J 1979 Oct2;147(7): 187-189.

14. Williams JA, Billington RW. A new technique for measuring the radiopacity of natural tooth substance and restorative materials. J Oral Rehabil 1987 May;14(3):267-269.

15. Watts DC. Characterization of aluminium radiopacity standards for restorative materials. J Dent 1987 Aug;15(4):175-177.

16. Pedrosa RF, Brasileiro IV, dos Anjos Pontual ML, dos Anjos Pontual A, da Silveira MM. Influence of materials radiopacity in the radiographic diagnosis of secondary caries: evaluation in film and two digital systems. Dentomaxillofac Radiol 2011 Sep;40(6):344-350.

17. Matteson SR, Phillips C, Kantor ML, Leinedecker T. The effect of lesion size, restorative material and film speed on the detection of recurrent caries. Oral Surg Oral Med Oral Pathol 1989 Aug;68(2):232-237.

18. Marouf N, Sidhu SK. A study on the radiopacity of different shades of resin-modified glass-ionomer restorative materials. Oper Dent 1998 Jan-Feb;23(1):10-14.

19. Sidhu SK, Shah PMM, Chong BS, Pitt Ford TR. Radiopacity of resin-modified glass-ionomer restorative cements. Quintessence Int 1996 Sep;27(9):639-643.

20. Van Dijken JWV, Wing KR, Ruyter IE. An evaluation of the radiopacity of composite restorative material used in class I and II cavities. Acta Odontol Scand 1989 Dec;47(6): 401-407.

21. El-Mowafy OM, Brown JW, McComb D. Radiopacity of direct ceramic inlay restoratives. J Dent 1991 Dec;19(6):366-368.

22. Willems G, Noack MJ, Inokoshi S, Lambrechts P, Van Meerbeek B, Braem M, Roulet JF, Vanherle G. Radiopacity of composites with human enamel and dentine. J Dent 1991 Dec;19(6):362-365.

23. Toyooka H, Taira M, Wakasa K, Yamaki M, Fujita M, Wada T. Radiopacity of 12 visible-light-cured dental composite resins. J Oral Rehabil 1993 Nov;20:623-625.

24. Bouschlicher MR, Cobb DS, Boyer DB. Radiopacity of compomers, flowable and conventional resin composites for posterior restorations. Oper Dent 1999 Jan-Feb;24(1):20-25.

25. Murchinson DF, Charlton DG, Moore WS. Comparative radiopacity of flowable resin composites. Quintessence Int 1999 Mar;30(3):179-184.

26. Hara AT, Serra MC, Rodrigues AL Jr. Radiopacity of glassionomer/composite resin hybrid materials. Braz Dent J 2001;12(2):85-89.

27. American National Standard/American Dental Association specification no 27 for resin-based filling materials. Chicago: American Dental Association, Council on Scientific Affairs; 1993. 